\title{
Enfermería y COVID
}

\section{Nursing and COVID}

\begin{abstract}
Autora:
Maciá Soler, Loreto ${ }^{1}$

1. Universidad de Alicante. España. ORCID: http://orcid.org/0000-0002-1801-7607. Correo electrónico: loreto.macia@ua.es
\end{abstract}

Palabras clave: enfermería; cuidados; covid.

Keywords: nursing; care; covid.

Afortunadamente, en la sociedad cada vez se da más importancia al conocimiento científico y este mensaje supone un avance social, como lo es, el aumento de edad para la enseñanza obligatoria o las garantías sanitarias y sociales para toda la población. Tanto la educación como la búsqueda del conocimiento resultan una buena terapia para fomentar el respeto entre personas desde la mejora individual y por extensión de esta idea, si mejoramos como personas, haremos un planeta mejor.

La pandemia COVID nos ha traído tragedia y avance científico como suele pasar en cualquier cataclismo y lo que se está viviendo con esta enfermedad, sin duda es comparable a un desastre natural o a una contienda, pero nos está aportando avances científicos importantes, no solo en relación con la virología, o la inmunología, sino también con la tecnología, cambios de hábitos de vida y desde luego formas de cuidar.

Puede citar este artículo como: Maciá Soler L. Enfermería y COVID. RECIEN. Revista Científica de Enfermería. 2020; 20: 1-2. https://doi.org/10.14198/recien.2020.20.01 
Me detengo en el cuidado de las personas enfermas que, por mi profesión enfermera es una de las cuestiones que en este momento me hacen sentir mayor sensibilidad.

La pandemia nos está aportando una oportunidad de cuidar mejor, de asumir la responsabilidad del paciente durante los procesos de hospitalización que, en muchas ocasiones, son largos y además nos está aportando a las enfermeras una capacidad para liderar los cuidados relacionados con la perdida de autonomía de estas personas enfermas, fuera de lo común; tan excepcional como lo es la propia situación que estamos viviendo.

Cada vez que un paciente hospitalizado por COVID recibe su alta con unos efectos adversos mínimos provocados por la hospitalización, es porque los cuidados de enfermería recibidos han colaborado a evitar estos efectos adversos.

Desde la atención primaria de salud, el trabajo que se está realizando en atención domiciliaria y vacunación es muy importante para la población; un auténtico servicio de cuidados. Gracias por estar ahí, queridas colegas.

Como responsables tanto de prevenir los efectos adversos que se pueden producir durante la hospitalización, como de llevar adelante una atención domiciliaria excelente y una vacunación profesional y además, en estos momentos tan intensos de trabajo quiero animar desde esta editorial a todas mis colegas enfermeras clínicas a continuar ejerciendo esta profesión tan magnifica con el rigor y el buen hacer que estáis demostrando.

Loreto Maciá. Editora.

Enfermera Doctora. Profesora de gestión.

Departamento de enfermería. Universidad de Alicante 